\title{
Impact of containment following COVID -19 on hospitalization activities in the pediatric surgical emergencies department, children's hospital of Rabat.
}

\author{
Loubna Aqqaoui ${ }^{1,2,3,4}$, Toualouth Lafia ${ }^{1,2,6}$, Aya Skiredj ${ }^{1,2}$, Fadwa Boughaleb ${ }^{1,2}$, Omar Dalero $^{5}$, Hicham Zerhouni ${ }^{1,2}$, Fouad \\ Ettayebi ${ }^{1,2}$, Souad Lebar ${ }^{3}$, Houda Oubejja ${ }^{1,2,3,4}$ \\ 1-Department of pediatric surgical emergencies, children's hospital of Rabat, Morocco. \\ 2-Faculty of medicine and pharmacy, University Mohammed V, Rabat, Morocco. \\ 3-Laboratory of Genetic and Biometry, faculty of science, university Ibn Tofail Kenitra, Morocco. \\ 4-Laboratory of epidemiology, clinical research and Biostatistics, faculty of medicine and pharmacy, University Mohammed V, Rabat. \\ 5-Pediatric surgery department, university hospital center, Tanger-Tetouan-Housseima region \\ 6-Ministry of health, Republic of Benin.
}

\begin{abstract}
The Covid-19 pandemic has put stress on the healthcare system with a major impact on access to healthcare. The aim is to study the impact of containment on the hospitalization of children in the pediatric surgical emergency department, Children's Hospital of Rabat. Material and methods: A retrospective study was carried out of children admitted at the Pediatric Surgical Emergencies Department (PSE), over a period of 6 months. The data were entered and analyzed by statistical software Jamovi 1.6.23. A chi-square test was used to compare the variables between the two periods: before and during containment. Results: We identified 579 children hospitalized during the first semester of 2020. The median age was 5 years [1-10] with predominance of boys $(66.1 \%)$. Admission diagnosis are represented by abdominal emergencies $(36.8 \%)$, head trauma $(22.6 \%)$. Burns represent only $5,7 \%$. These diagnosis were divided into visceral surgical emergencies (42\%), trauma emergencies (48\%) and non-urgent pathologies $(10 \%)$. Surgery was done in $45.6 \%$. Visceral and trauma emergencies were equivalent before and during the containment. On the other hand, there was a slight increase for visceral emergencies ( $57 \%$ Vs $43 \%$ ) while the number of scheduled patients fell from $94.3 \%$ before containment to $5,7 \%$ during the containment.
\end{abstract}

Keywords; covid19, hospitalization, confinement, children, $\quad$ Morocco.

Introduction:

The first case of Covid 19 was detected in China in December 2019, on March 11, 2020, the WHO declared the status of a global pandemic [1]. In Morocco, the first patient was detected on March $02^{\text {nd }}$. The Moroccan government had declared a global containment from March 23 ${ }^{\text {rd }}, 2020$ [2]. Consequently imposing strict measures to limit the movement of citizens and thus the transmission of the virus.

There is no doubt that the Covid-19 pandemic has had an unprecedented impact on all aspects of life, and more deeply in the medical field [3]. Consequently, access to care structures and technical facilities has been disrupted. The saturation of emergency and intensive care services by COVID patients, the lack of material and human resources resulted in postponement of "nonCovid" patients [4-6]
During this period, the pediatric surgical emergencies (PSE) department continued to provide the usual services and care to patients 24 hours a day, respecting the instructions established by the World Health Organization and the Moroccan Ministry of Health. A special COVID-19 circuit was established in the emergency room (ER), the protection of patients, as well as the staff (Facial masks, protective measures, disinfectant etc).

The aim of this paper is to describe the impact of the containment on the activities of the pediatric surgical emergencies (PSE) department, Children's Hospital of Rabat.

Material and methods:

- Population 
This is a cross-sectional study, carried out in the PSE Department; involving children hospitalized during the first semester of the year 2020. An exploitation sheet has been drawn up.

- Variables

The admission diagnosis were arthritis, acute abdomen (Abdominal emergencies such as appenditis, peritonitis, abdominal trauma, occlusion, intestinal malrotation, volvulus ...etc), head trauma (Defined as any kind of damage to the scalp, skull, brain, or other tissue and blood vessels in the head), burn (defined as a type of injury caused by heat, which can be thermal, electrical, chemical or electromagnetic energy), fracture (Is a partial or complete break in the bone), Polytrauma (Polytrauma is one or more traumatic injuries, at least one of which is life threatening). These diagnosis were divided into visceral surgical emergencies, trauma emergencies and non-urgent pathologies.

We have also distinguished two periods; the period before the containment, corresponding to the first quarter of 2020, and the period of containment ( $2^{\text {nd }}$ trimester). The Shapiro-Wilk test was used to study the distribution of quantitative variables, which are expressed as median and interquartile ranges if non-Gaussian distribution. Qualitative variables were expressed in number and percentage. The significance level was set at $5 \%$.

\section{- Statistical analysis}

All of the data collected was entered and analyzed by Jamovi 1.6.23 software [7,8]. The chi-square test was used to compare the different characteristics according to the two periods, before and during containment.

\section{Results:}

We identified 579 children, hospitalized during the first semester of the year 2020. The median age was 5 years [1-10] with male predominance $(33.9 \%$ girls and $66.1 \%$ boys).

Figure 1 shows the decrease of the number of hospitalization during the first semester. Indeed, the number of patients admitted at the PSE department ranged from 129 to 165 patients in Januay and February. It fell sharply to 53 cases during Marsh, to increase slowly thereafter. The late June saw a higher number of admissions, around 97 patients.

Admission diagnosis were represented by acute abdomen (addominal emergencies) (36.8\%), head trauma (22.6\%), fractures $(13.3 \%)$ and polytrauma $(9.3 \%)$. Neonatal pathologies represent $9.7 \%$, followed by burns $(5.7 \%)$ (Figure 2). Regarding the pathology groups, the visceral surgical emergencies represented $42 \%$, trauma emergencies counted for $48 \%$ followed by non-urgent pathologies (10\%) (Figure 3). The surgery was done in $48.3 \%$ of cases (Figure 3 ).

The table 1 summariezes the general characteristics of the population.

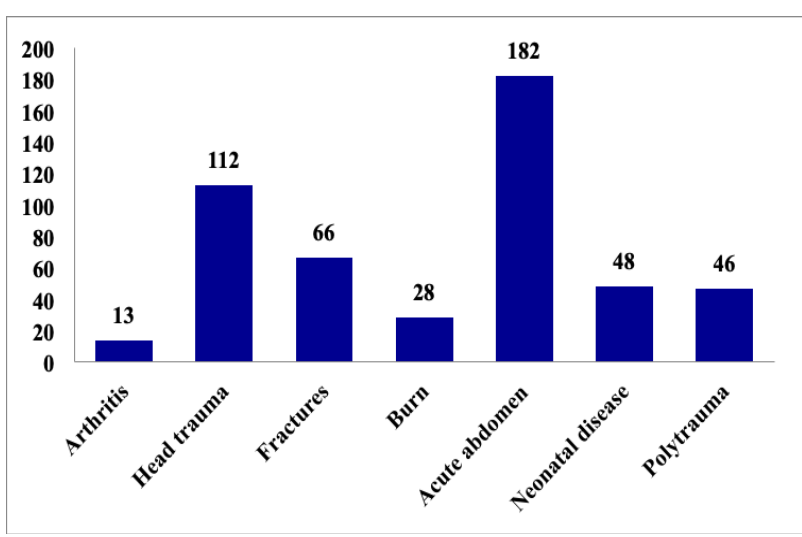

Figure 2: Bar graph representing the admission's diagnosis, among patient hospitalized during the first semester of 2020, PSE department, Children's hopsital of Rabat.

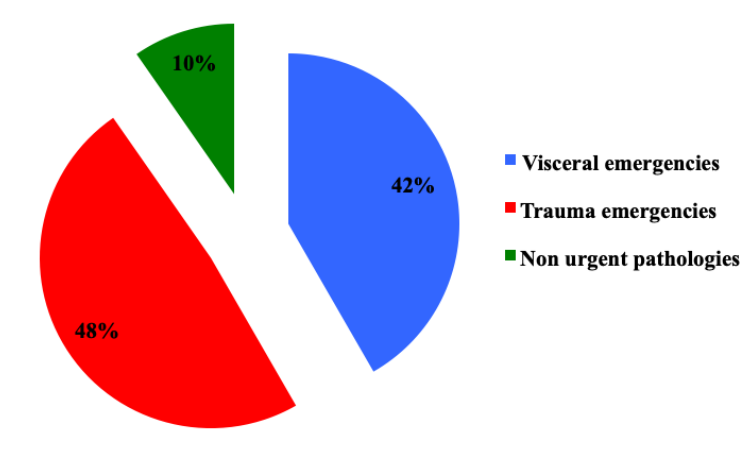

Figure 2: Distribution of patients according to the "urgent" or "non urgent" pathologies, hospitalized during the first semester of 2020, PSE department Children's hopsital of Rabat.

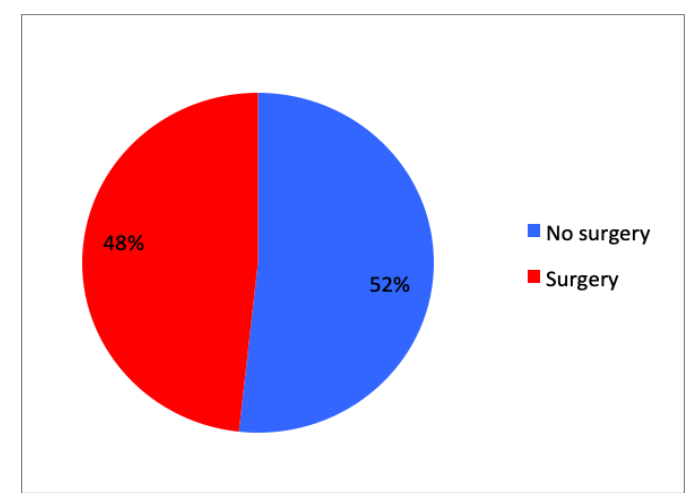

Figure 3: Distribution of patients according to the surgical or not surgical management, patients hospitalized during the first semester of 2020, PSE department Children's hopsital of Rabat. 


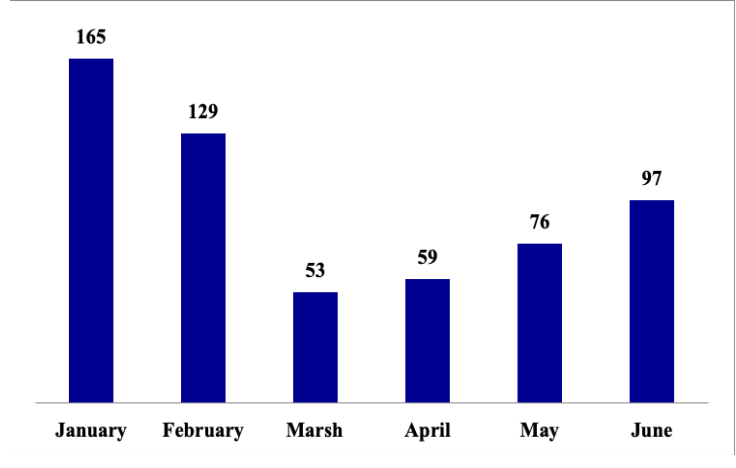

Figure 1: Evolution of the number of hospitalized patients during the first semester of 2020, PSE department Children's hopsital of Rabat.

Furthermore, as shown on table 2, before the containment acute abdomen came first in admissions diagnosis, representing $33 \%$ of all cases combined, followed by head trauma (26\%) and fractures $(17,4 \%)$. Bipolar truama and burns represented respectively $7 \%$ and $3 \%$. During the containment, these pourcentage changed. Indeed, the acute abdomen raised to $41,3 \%$ while the head trauma represented $18,7 \%$. Furtheremore, the polytrauma and burns increased their pourcentages (respectively 12\% and 9\%) (Figure 5). All these differences are statistically significant $(<\mathbf{0 , 0 0 1})$.

Regarding the pathology groups, the visceral surgical emergencies represented $36 \%$ before the containment versus $50 \%$ during the containment. The trauma emergencies remained stable during the two periods, while the non-urgent pathologies fell from $16 \%$ to $1 \%$.

In addition, the length of hospitalization of patients in the service remained stable before and during the containment.
Table 1: General characteristics of the the patients admitted at the PSE department, during the first semester 2020.

\begin{tabular}{lc}
\hline Variables & n 579 \\
\hline Age $^{\S}$ (months) & $60[11-120]$ \\
Gender* $^{*}$ & \\
Female & $196(33,9 \%)$ \\
Male & $383(66,1 \%)$
\end{tabular}

Admissions Diagnosis*

Arthritis

$13(2,6 \%)$

Head trauma

$112(22,6 \%)$

Fractures

$66(13,3 \%)$

Burn

$28(5,7 \%)$

Acute abdomen

$182(36,8 \%)$

Neonatal disease

$48(9,7 \%)$

Polytrauma

$46(9,3 \%)$

Hospital stay*

$<48$ hours

$305(52,8 \%)$

$>48$ hours

$273(47,2 \%)$

Pathology groups*

Visceral emergencies

$228(41,7 \%)$

Trauma emergencies

$266(48,6 \%)$

Non-urgent pathology

$53(9,2 \%)$

Surgery*

No surgery

$283(51,7 \%)$

Yes

$264(45,6 \%)$

Months*

January

$165(28,5 \%)$

February

$129(22,3 \%)$

Marsh

$53(9,2 \%)$

April

$59(10,2 \%)$

May

$76(13,1 \%)$

June

$97(16,8 \%)$

\section{Containment*}

Before Containment

347 (59,9\%)

Containment

$232(40,1 \%)$

$\S$ Variable expressed in median and quartiles

* Variable expressed in number and percentage 


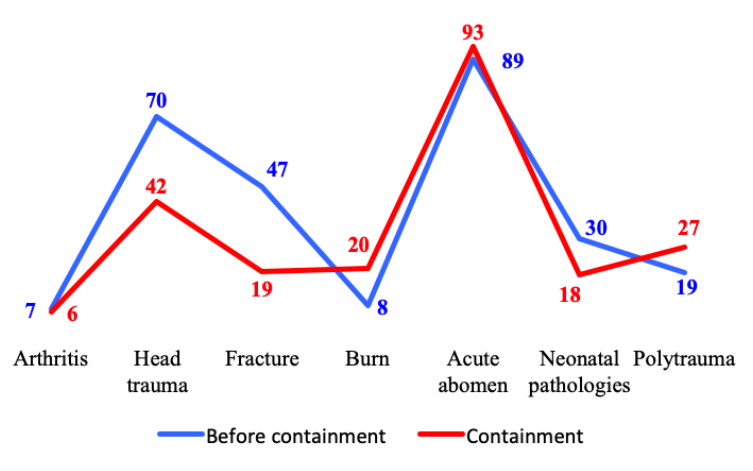

Figure 5: showing the distribution of admissions diagnosis according to the containment $(\mathrm{p}<0,001)$, PSE department, Children hospital of Rabat, 2020.

Table 2: Comparison of admission's diagnosis, the hospital stay and emergencies groups among hospitalized patients, before and during the containment period,PSE department, Children's hopsital of Rabat.

\begin{tabular}{|c|c|c|c|}
\hline & $\begin{array}{c}\text { Before } \\
\text { containment } \\
\mathrm{n}(\%)\end{array}$ & $\begin{array}{c}\text { Containme } \\
\text { nt } \\
n(\%)\end{array}$ & \\
\hline Admissions Diagnosis & & & $<0,001$ \\
\hline Arthritis & $7(2,6)$ & $6(2,7)$ & \\
\hline Head trauma & $70(25,9)$ & $42(18,7)$ & \\
\hline Fracture & $47(17,4)$ & $19(8,4)$ & \\
\hline Burn & $8(3)$ & $20(8,9)$ & \\
\hline Acute abdomen & $89(33)$ & $93(41,3)$ & \\
\hline Neonatal pathologies & $30(11,1)$ & $18(8)$ & \\
\hline Polytrauma & $19(7)$ & $27(12)$ & \\
\hline Pathology groups & & & $<\mathbf{0 , 0 0 1}$ \\
\hline Visceral emergencies & $113(36)$ & $115(50)$ & \\
\hline Trauma emergencies & $152(48)$ & $114(49)$ & \\
\hline Non urgent pathologies & $50(16)$ & $3(1)$ & \\
\hline Hospital stay & & & 0,681 \\
\hline$<48$ hours & $185(53,5)$ & $120(51,7)$ & \\
\hline$>48$ hours & $161(46,5)$ & $112(48,3)$ & \\
\hline
\end{tabular}

\section{Discussion:}

The strict measures imposed in each country from the start of the Covid-19 pandemic reduced the movements of citizens as much as possible and also imposed a reorganization of care services and a redeployment of health personnel; to cope with the growing number of patients admitted to the various health facilities.

Given these data, several studies have assessed the impact of the health crisis during its peak epidemic on surgical activity, especially during the period of the lockdown. In Seattle, United States, the average weekly surgical volume in a vascular surgery unit decreased by $71.7 \%$ [7]. In Milan, Italy, in maxillofacial surgery units, outpatient surgery decreased by $86 \%$ and conventional surgery by $78 \%$ [8]. In San Francisco, the general surgery department reduced its operating room activity by $80 \%$ [9]. In Marseille, France, during the first month of lockdown, the number of cases of spine surgery fell by almost $50 \%$ [10]. Similar results, especially on the number of consultations, have been reported in urological surgery by Motterle et al. [11]. In Tunisia, a study found a significant impact of containment on urgent surgical practices (compared to a previous period) with a significant reduction in emergency room admissions. A plausible explanation would be a fear of contamination of the population by potential patients encountered in hospital, despite the sometimes presence of urgent pathologies [12].

At the children's hospital of Rabat, a study published by the pediaric medical emergencies team found a low number of consultations. However, the number of overall consultations decreased by $74 \%$ between the two periods (4232 vs $1110 ; \mathrm{p}<0.005)$. This decrease could easily reflect the "non-urgent" consultations that traditionally arrive in any emergency department. However, the number of hospitalizations has also decreased (811 in 2019 against 471 in 2020, decrease of $41.9 \%, p<0.005)$ since containment measures were put in place due to COVID-19 [13].

Within the same hospital structure, the PSE department continued to receive urgent patients 24 hours a day. We noted a sudden decrease in patients consulting emergency rooms, and this can be explained by the drastic containment measures but also probably by the anxiety of parents to bring their children back to care services [14]. In addition, patients with elective pathologies who were used to overcrowding emergencies disappeared during this period. In the same register, we noted a decrease in patients scheduled for visceral surgery $(15.9 \%$ compared to $1.3 \%)$ during containment, thanks to the policy of the service and the recommendations of the Ministry of Health, which encouraged the reduction or even cancellation of 
scheduled interventions. That has been found in several countries [15-17]. In addition, patients who had semiurgent pathologies requiring surgery were operated on within two days of their admission, aiming to limit the movement of companions on the one hand and reduce the hospital stay on the other. These guidelines were approved by The American College of Surgeons, elective surgery should only be performed if it is necessary, to avoid prolonged hospitalization or further readmissions to the hospital. The aim is to reduce the preoperative period and ensure early discharge [18, 19].

Also, the number of head trauma and fractures related mostly to everyday life accidents, often occurring outside the home has been reduced during periods of containment. This observation could be explained by the reduction in the movements of citizens. In addition, burns have increased, this could be explained by the fact that children confined to their homes are more prone to domestic accidents.

\section{Conclusion:}

The COVID-19 pandemic has a major impact on the daily life of everyone, patients and healthcare professionals. Our study highlighted the impact of this health crisis on the organization of our service which is superimposed on that of the world. Thus, it will be necessary to adapt the priorities and the strategies to guarantee a quality of care and especially access to hospitals for all.

\section{References:}

1. KG. Andersen, A. Rambaut, WI. Lipkin, EC. Holmes, RF. Garry. The proximal origin of SARS-CoV-2. Nat Med. ; 26(4): 450-452(2020 Apr). PubMed| Google Scholar.

2. Royaume du Maroc. Epidémie du COVID-19 au Maroc: situation épidémiologique. (03 avril 2020). Accessed July 6, 2020

3. B. Stoecklin S, P. Rolland, Y. Silue, et al. First cases of coronavirus disease 2019 (COVID-19) in France: surveillance, investigations and control measures. Euro Surveill 2020;25. (January 2020)

4. https://www.gouvernement.fr/infocoronavirus.

5. G. Fiorino, M. Allocca, F. Furfaro, et al. Inflammatory Bowel Disease Care in the COVID-19 Pandemic Era: The Humanitas, Milan, Experience. (2020 Mar 24).
6. DL. Heymann, N. Shindo. COVID-19: what is next for public health? Lancet;395:542 - 5 (2020)

7. JF. Hemingway, N. Singh, BW. Starnes. Emerging Practice Patterns in Vascular Surgery During the COVID-19 Pandemic. J Vasc Surg (2020).

8. F. Allevi, A. Dionisio, U. Baciliero, et al. Impact of COVID-19 epidemic on Maxillofacial Surgery in Italy. Br J Oral Maxillofac Surg (2020).

9. EM. Lancaster, JA. Sosa, A. Sammann, et al. Rapid Response of an Academic Surgical Department to the COVID-19 Pandemic: Implications for Patients, Surgeons, and the Community. J Am Coll Surg (2020). Available from:https://www.ncbi.nlm.nih.gov/pmc/article s/PMC7194622/.

10. M. Meyer, S. Prost, K. Farah, et al. Spine surgical procedures during coronavirus disease 2019 pandemic: is it still possible to take care of patients? Results of an observational study in the first month of confinement. Asian Spine J (2020).

11. G. Motterle, A. Morlacco, M. Iafrate, et al. The impact of COVID-19 pandemic on urological emergencies: a single-center experience. World J Urol : 1—5, (2020)

12. S. Atri, A. Hadad, A. Makni, M. Jamel Kacem. Les urgences digestives sont profondément impactées et plus graves durant la pandémie de COVID-19virale. Département de chirurgie digestive " $A$ », La Rabta Hospital University, Faculty of Medicine of Tunis La Rabta Jebbari, 1007 Tunis, (Tunisie)

13 N. Mekaoui, R. Razine, Q. Bassat, B. Sououd Benjelloun, and L. Karboubi, The Effect of COVID-19 on Paediatric Emergencies and Admissions in Morocco: Cannot See the Forest for the Trees? Journal of Tropical Pediatrics, (2020)

14 R. Migliani, S. Keïta, B. Diallo, S. Mesfin, W. Perea, B. Dahl, et al. Aspects épidémiologiques de la maladie à virus Ébola en Guinée. Bull Soc Pathol Exot 109:218-35, (2016) http://dx.doi.org/10.1007/s13149-016-0511-4

15 E. Kelly, Z. Firt. How is COVID-19 changing the use of emergency care? on https://www.health.org.uk/news-and- 
comment/charts-and-infographics/how-iscovid-19-changing-the-use-of-emergency-care.

16 Un système de santé focalisé sur une pathologie au détriment des autres: une crise sanitaire en cache-t-elle une autre? Santé publique: pour un nouveau départleçons de l'épidémie de covid-19- Rapport. on http://www.senat.fr/rap/r20-199-1/r20-199111.html

17 F. Pecoraro, D. Luzi, F. Clemente. The efficiency in the ordinary hospital bed management: A comparative analysis in four European countries before the COVID-19 outbreak. PLoS ONE 16(3): e0248867. https://doi.org/ 10.1371/journal.pone.0248867 (2021).

18 American College of Surgeons, COVID-19 Guidelines for Triage of Pediatric Surgery Patients, (2020) https://www.facs.org/covid19/clinical-guidance/elective-case/ Pediatric Surgery Accessed April 2, 2020.

19 A. Al-Jabira, A. Kerwana, M. Nicolab, Z. Alsafic , M. Khanc , C. Sohrabid, N. O'Neilld, C. Iosifidisd, M. Griffine, G. Mathewc, R. Aghaf, Impact of the Coronavirus (COVID-19) pandemic on surgical practice - Part 2 (surgical prioritisation) international journal of Surgery 79 233-248 (2020) 